\title{
Kinematic Changes in Swallowing After Surgical Removal of Anterior Cervical Osteophyte Causing Dysphagia: A Case Series
}

\author{
Hyeonghui Jeong, $\mathrm{MD}^{1}$, Han Gil Seo, $\mathrm{MD}^{1}$, Tai Ryoon Han, MD, $\mathrm{PhD}^{1}$, \\ Chun Kee Chung, MD, $\mathrm{PhD}^{2}$, Byung-Mo Oh, MD, $\mathrm{PhD}^{1}$
}

Departments of ${ }^{1}$ Rehabilitation Medicine and ${ }^{2}$ Neurosurgery, Seoul National University College of Medicine, Seoul, Korea

This retrospective case series included five patients who underwent surgical resection of the cervical anterior osteophyte due to dysphagia. Videofluoroscopic swallowing studies (VFSSs) were performed before and after surgery on each patient, and kinematic analysis of the video clips from the VFSS of a 5-mL liquid barium swallow was carried out. Functional oral intake improved after surgery in 3/4 patients who had required a modified diet before surgery. Kinematic analysis showed increases in the maximal hyoid vertical movement length (13.16 \pm 5.87 to $19.09 \pm 4.77 \mathrm{~mm}, \mathrm{p}=0.080$ ), hyoid movement velocities $(170.24 \pm 84.71$ to $285.53 \pm 104.55 \mathrm{~mm} / \mathrm{s}, \mathrm{p}=0.043)$, and upper esophageal sphincter opening width $(3.97 \pm 0.42$ to $6.39 \pm 1.32 \mathrm{~mm}, \mathrm{p}=0.043)$ after surgery. In conclusion, improved upper esophageal sphincter opening via enhancement of hyoid movement after cervical anterior osteophyte resection may be the kinetic mechanism of improved swallowing function.

Keywords Deglutition disorders, Osteophyte, Hyoid bone

\section{INTRODUCTION}

Anterior cervical osteophytes are commonly observed in the elderly. Approximately one-third of all individuals over 60 years of age have anterior cervical osteophytes, which are associated with vertebral degenerative disease and diffuse idiopathic skeletal hyperostosis (DISH) [1].

Received April 10, 2014; Accepted June 16, 2014

Corresponding author: Byung-Mo Oh

Department of Rehabilitation Medicine, Seoul National University College of Medicine, 101 Daehak-ro, Jongno-gu, Seoul 110-744, Korea Tel: +82-2-2072-2619, Fax: +82-2-743-7473, E-mail: keepwiz@gmail.com

(c) This is an open-access article distributed under the terms of the Creative Commons Attribution Non-Commercial License (http://creativecommons. org/licenses/by-nc/3.0) which permits unrestricted noncommercial use, distribution, and reproduction in any medium, provided the original work is properly cited.

Copyright $\odot 2014$ by Korean Academy of Rehabilitation Medicine
Although they are usually asymptomatic, dysphagia is the most common presentation of symptomatic anterior cervical osteophytes [2]. Several cases have been described regarding the effect of surgical management on symptomatic osteophytes, but evidence for the surgical approach remains insufficient. One argument against surgical management is that changes in laryngopharyngeal function cannot be reversed by surgery, because the osteophytogenesis is a slow, progressive degenerative condition influencing characteristics of the surrounding soft tissue [3]. Kinematic analysis has the advantage of demonstrating the mechanical effects of surgical removal on the laryngopharynx in detail by providing the specific quantitative changes of each structure, such as the epiglottis and upper esophageal sphincter.

We present the first description of the quantitative 
kinematic changes after surgical resection of anterior osteophytes in five patients who underwent surgery to alleviate dysphagic symptoms.

\section{CASE REPORT}

We retrospectively reviewed all surgical resection of anterior cervical osteophyte cases between March 2009 and March 2013 that underwent videofluoroscopic swallowing study (VFSS) in our hospital. Among the 4,979 VFSS cases, only six patients underwent surgical anterior cervical osteophyte resection. All six patients were referred to a neurosurgeon with videofluoroscopic evidence showing that their dysphagia was significantly attributed to anterior cervical osteophytes. Medical records of each patient were reviewed in order to eliminate cases of dysphagia due to neurological factors, and a case with Parkinson disease who had a previous history of endotracheal intubation was excluded. Four patients (cases 1, 2, 3 , and 4) were hospitalized in the rehabilitation ward and underwent daily conventional swallowing therapy for a week before the operation and for four weeks after the operation. In the daily conventional swallowing therapy, oral exercise, laryngeal elevation exercise, chin tuck, supraglottic swallowing, and Shaker exercise education were included. However, since the fifth patient had better swallowing function, he only had four swallowing therapy sessions according to VFSS findings during the postoperative care.

This series included five men (mean age, 72.0 years; range, 63-83 years). All cases had swallowing difficulty and one patient had tingling pain in all extremities caused by coexistent cervical myelopathy from a thickened ossified posterior longitudinal ligament (OPLL) (Table 1).

The osteophytes were well visualized on plain lateral radiographs and with 3-dimensional computed tomography. The osteophytes were classified into three types based on the plain lateral radiographs: segmental, continuous, or mixed [4]. We classified four cases as segmental type and one case as mixed type [4] (Fig. 1). The upper margin of the osteophytes were between the C3 and C5 vertebral bodies. The thickest level of the osteophyte was C5-6 in four cases and C4-5 in one case. The mean osteophyte thickness was $10.10 \mathrm{~mm}$ (range, $5.62-15.93 \mathrm{~mm}$ ) (Table 1).

Several clinical outcomes were evaluated before and after surgery, such as initial diet, diet recommendation, videofluoroscopic dysphagia scale (VDS) [5], and the amount of pyriform sinus residue. In this study, the VFSSs between 8-12 weeks after surgery were used as postoperative evaluations.

The kinematic analysis was performed on a 5-mL diluted barium solution swallow according to a prior study [6]. The anterior margin of the hyoid bone, the base and tip margin of the epiglottis, the anterior-superior margin of the subglottic air column, and the esophageal upper sphincter opening were digitally coordinated at each frame using the motion analysis software system APAS (Ariel Dynamics Inc., Trabuco Canyon, CA, USA). As the upper esophageal sphincter is located usually at the C5-6 level [6], the digital mark for upper esophageal sphincter was defined at an imaginary perpendicular line bisecting the C5-6 intervertebral space. The maximal excursions

Table 1. Summary of 5 patients with anterior cervical osteophyte

\begin{tabular}{|c|c|c|c|c|c|c|}
\hline & \multirow[b]{2}{*}{ Age/sex } & \multicolumn{5}{|c|}{ Radiologic finding } \\
\hline & & Affected level & $\begin{array}{c}\text { Thickest } \\
\text { level }\end{array}$ & $\begin{array}{c}\text { Osteophyte } \\
\text { thickness (mm) }\end{array}$ & $\begin{array}{l}\text { Osteophyte } \\
\text { type }\end{array}$ & Comorbidity \\
\hline Case 1 & $76 / \mathrm{M}$ & C3-4-5 & C4-5 & 10.58 & Segmental & $\begin{array}{r}\text { Chronic obstructive } \\
\text { pulmonary disease }\end{array}$ \\
\hline Case 2 & $83 / \mathrm{M}$ & $C 4-5-6-7$ & C5-6 & 5.62 & Mixed & $\begin{array}{l}\text { Diabetes mellitus } \\
\text { Depression }\end{array}$ \\
\hline Case 3 & $73 / \mathrm{M}$ & $\mathrm{C} 3-4-5-6-7$ & $\mathrm{C} 5-6$ & 15.93 & Segmental & $\begin{array}{l}\text { Pancreatic cystic tumor } \\
\text { Benign prostate hyperplasia }\end{array}$ \\
\hline Case 4 & $63 / \mathrm{M}$ & C3-4-5-6-7-T1 & C5-6 & 11.34 & Segmental & $\begin{array}{l}\text { Hypertension } \\
\text { Diabetes mellitus } \\
\text { Angina }\end{array}$ \\
\hline Case 5 & $65 / \mathrm{M}$ & $\mathrm{C} 5$ & C5-6 & 7.02 & Segmental & Hypertension \\
\hline
\end{tabular}



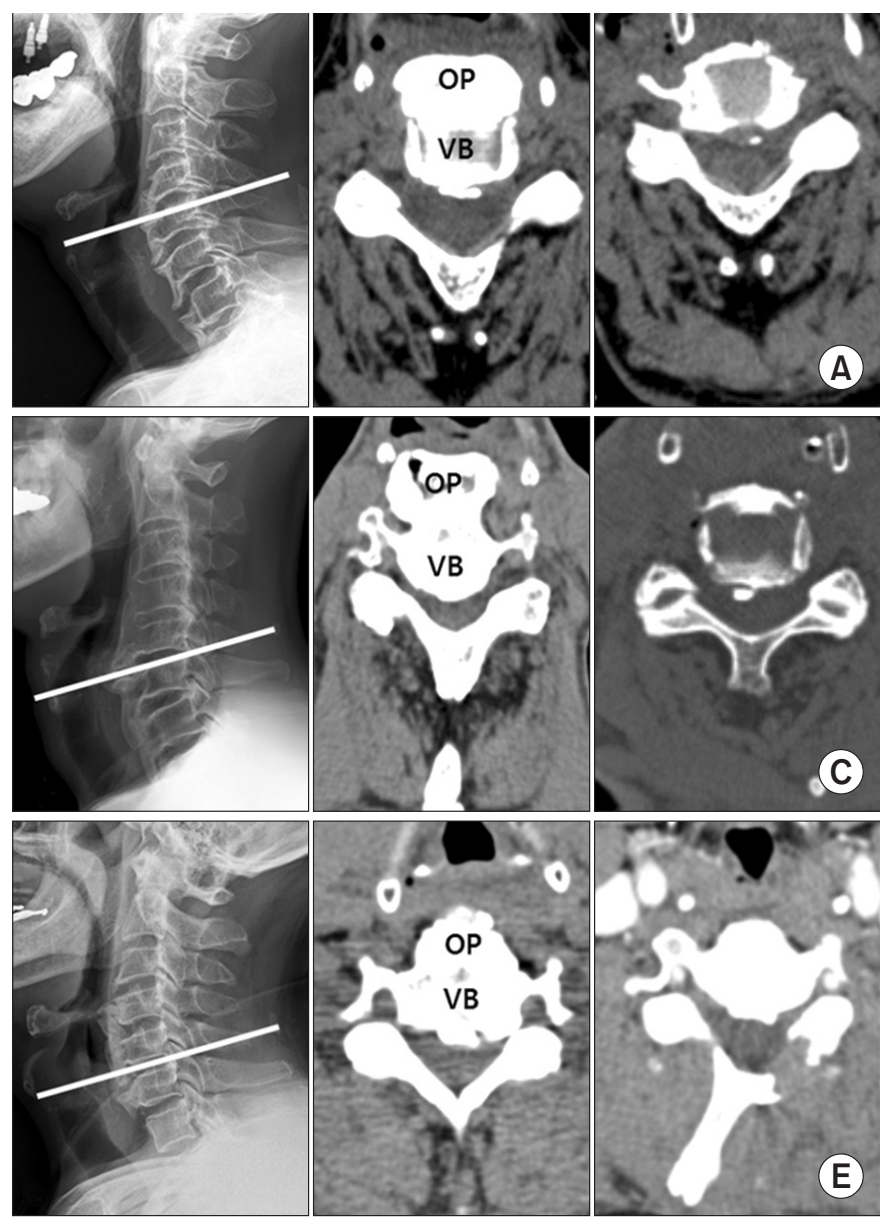
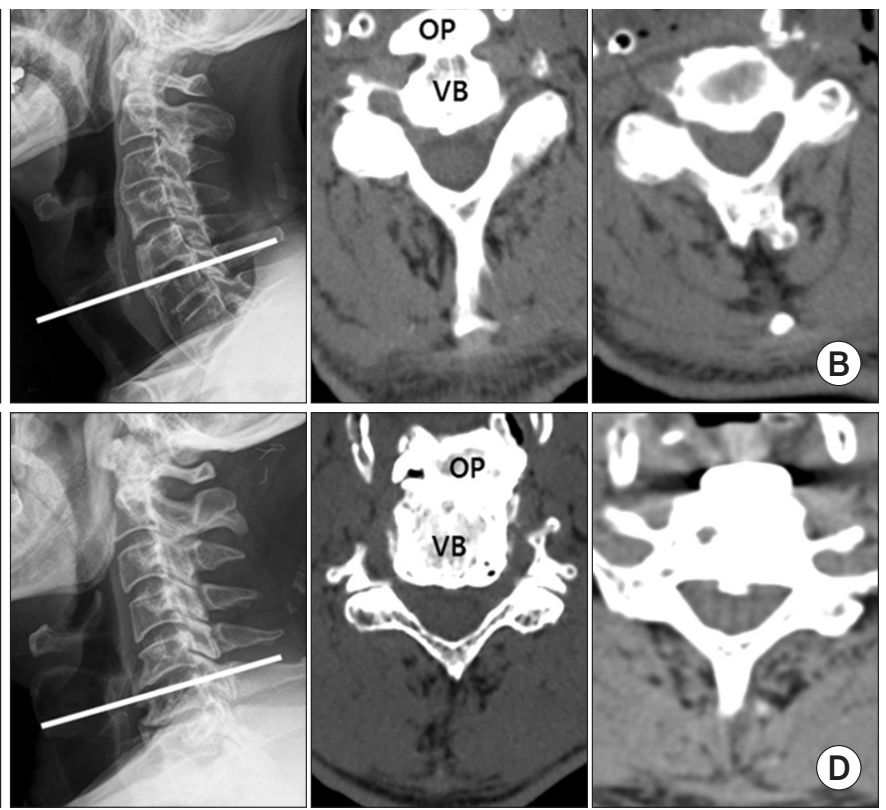

Fig. 1. Lateral view X-ray (left), preoperative CT (middle), and postoperative CT (right) images of cases. White lines indicate the section level of the CT image, which represents the thickest osteophyte. The level of the thickest osteophyte was C4-5 in 1 case (A) and C5-6 in 4 cases (BE). CT, computed tomography; VB, vertebral body; OP, osteophyte.

Table 2. Changes in swallowing function after surgical removal

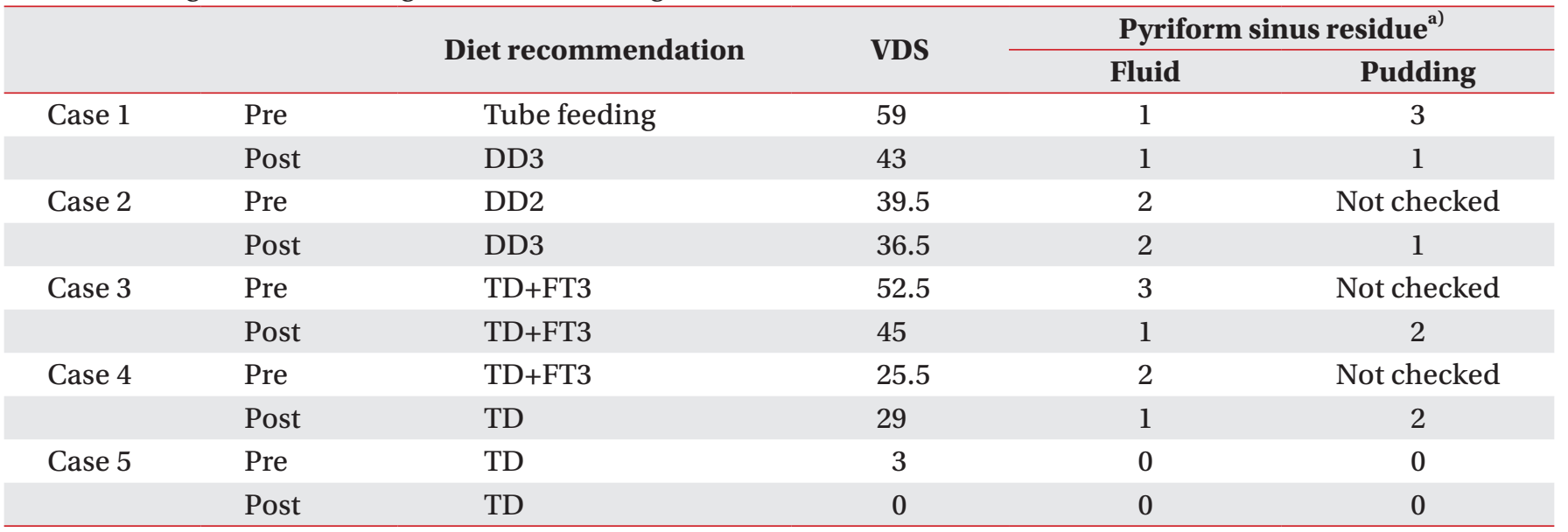

VDS, videofluoroscopic dysphagia scale; DD2, modified diet with honey-like thickness; DD3, modified diet with tomato juice-like thickness; TD, tolerable diet; FT3, fluid restriction with tomato juice-like thickness.

${ }^{a)}$ Grade 0 , no residue; grade $1,<10 \%$ of all widths of pyriform sinuses in the videofluoroscopic image; grade $2,10 \%$ $50 \%$ of width; grade $3,>50 \%$ of width. 
(A)

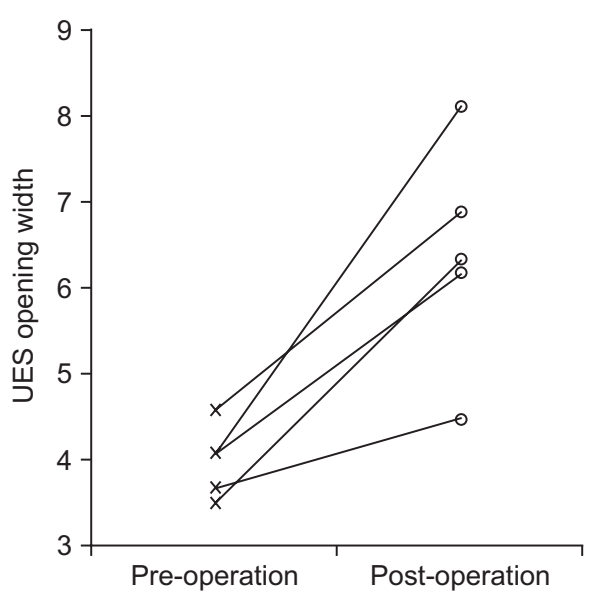

(C)

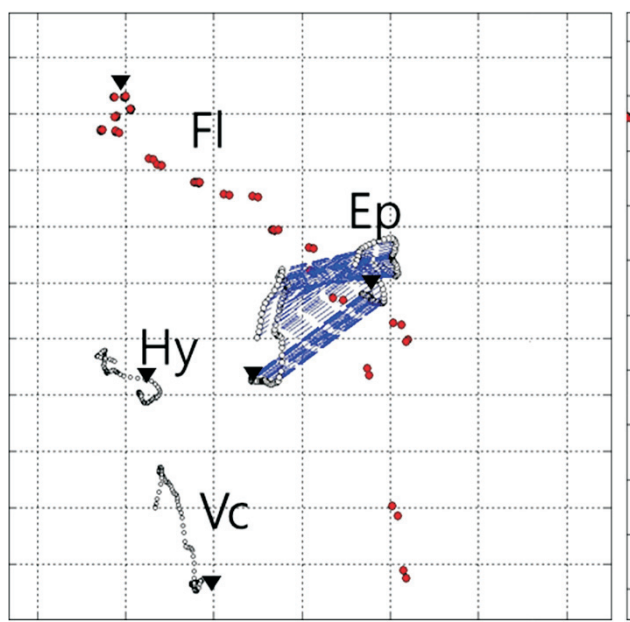

(B)

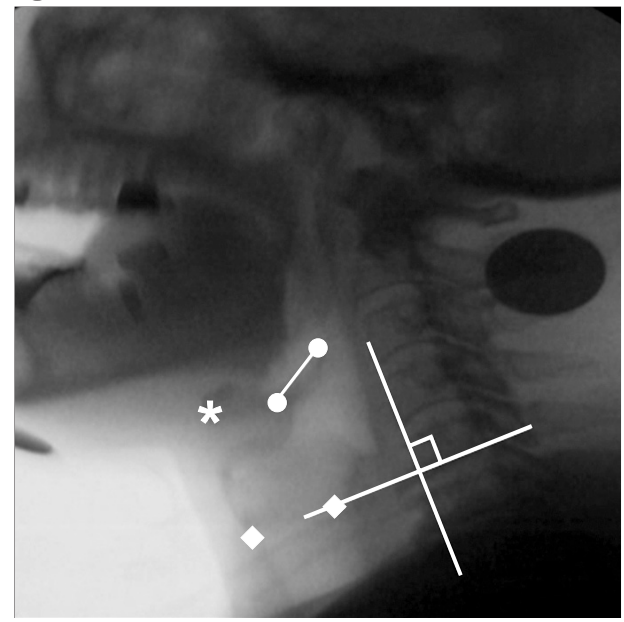

(D)

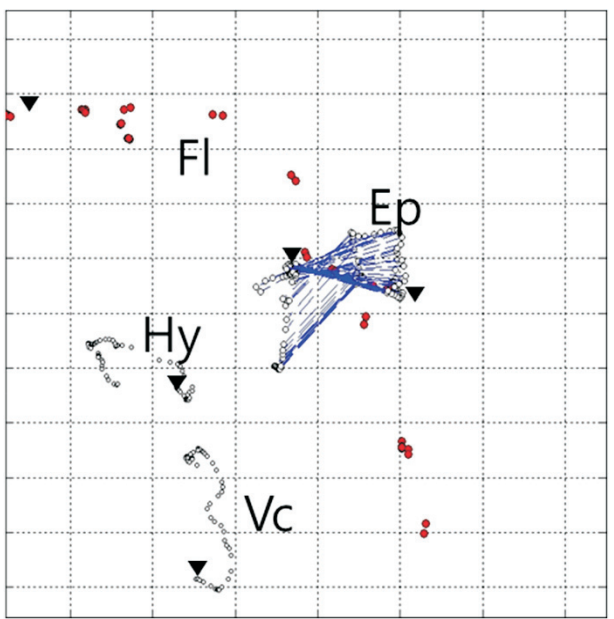

Fig. 2. Exemplary trajectories of the epiglottis. (A) The changes of UES opening width. (B) Cervical lateral view $\mathrm{x}$-ray with digital coordination $(\bullet$, epiglottis margin; *, anterior margin of hyoid bone; $\boldsymbol{\bullet}$, vocal fold margin; y-axis, a straight line connecting the anterior-inferior border of the 4 th cervical vertebra (the ' 0 ' point)). (C) Preoperative trajectory. (D) Postoperative trajectory. UES, upper esophageal sphincter; Fl, fluid; Ep, epiglottis; Hy, hyoid; Vc, vocal fold. $(\mathrm{cm})$ of the hyoid bone and the vocal fold, the rotation of the epiglottis, and the opening width of the upper esophageal sphincter were calculated. Measurements were taken using MATLAB R2007a (MathWorks, Natick, MA, USA) [6].

Wilcoxon signed-rank test was used to evaluate the kinematic change after surgery because of the small study size. Statistical analyses were performed with SPSS ver. 18.0 (SPSS Inc., Chicago, IL, USA).

Functional oral intake, as represented by the diet recommendation, improved after surgery in $3 / 4$ patients who had required a modified diet before surgery. The VDS score improved in four cases after surgery (mean VDS, $35.90 \pm 22.43$ to $30.70 \pm 18.27 ; \mathrm{Z}=-1.22, \mathrm{p}=0.223$ ) (Table 2 ).

The maximal hyoid vertical movement length (mean, $13.16 \pm 5.87$ to $19.09 \pm 4.77 \mathrm{~mm} ; \mathrm{p}=0.080$ ), hyoid movement velocity (mean, $170.24 \pm 84.71$ to $285.53 \pm 104.55 \mathrm{~mm} / \mathrm{s}$; $\mathrm{p}=0.043$ ), and upper esophageal sphincter opening width (mean width, $3.97 \pm 0.42$ to $6.39 \pm 1.32 \mathrm{~mm}$; $\mathrm{p}=0.043$ ) increased after surgery. The maximal velocity of fluid flow (mean, $417.81 \pm 184.54$ to $658.96 \pm 378.61 \mathrm{~mm} / \mathrm{s} ; \mathrm{p}=0.225$ ) and maximal length of subglottic air column vertical movement (mean, $21.12 \pm 4.99$ to $25.94 \pm 5.23 \mathrm{~mm}$; $\mathrm{p}=0.138$ ) increased in $3 / 5$ cases (Fig. 2). However, no consistent trend was observed in epiglottis folding changes (Table 3 ).

\section{DISCUSSION}

Progressive swallowing difficulty is the most common cervical anterior osteophyte symptom [2]. Many possible mechanisms explain the dysphagia caused by osteophytes, including direct impingement by large osteophytes, obstruction by local edema and inflammation, spasm of the adjacent cricopharyngeal structure, fibrosis 
Table 3. Changes in kinematic variables after surgical removal

\begin{tabular}{|lccc}
\hline & Preoperation & Postoperation & p-value \\
\hline Maximal distance and angle measure & & & \\
\hline Hyoid movement length $(\mathrm{mm})$ & & & \\
\hline Vertical & $13.16(5.87)$ & $19.09(4.77)$ & 0.080 \\
\hline Horizontal & $10.52(4.15)$ & $9.26(3.66)$ & 0.500 \\
\hline Subglottic air column movement length $(\mathrm{mm})$ & & & \\
\hline Vertical & $21.12(4.99)$ & $25.94(5.23)$ & 0.138 \\
\hline Horizontal & $4.90(1.61)$ & $4.88(0.93)$ & 0.686 \\
\hline Angle of epiglottis rotation $\left(^{\circ}\right)$ & $68.39(27.34)$ & $59.38(24.59)$ & 0.500 \\
\hline Upper esophageal sphincter opening width $(\mathrm{mm})$ & $3.97(0.42)$ & $6.39(1.32)$ & $0.043^{*}$ \\
\hline Maximal velocity measure $(\mathrm{mm} / \mathrm{s})$ & & & 0.225 \\
\hline Fluid flow & $417.81(184.54)$ & $658.96(378.61)$ & \\
\hline Hyoid movement & & & $0.043^{*}$ \\
\hline 2 Dimension & $170.24(84.71)$ & $285.53(104.55)$ & $0.043^{*}$ \\
\hline Vertical & $98.94(59.9)$ & $247.09(121.21)$ & 0.686 \\
\hline Horizontal & $77.36(54.69)$ & $87.95(32.48)$ & \\
\hline
\end{tabular}

Values are presented as mean (standard deviation).

${ }^{*} \mathrm{p}<0.05$ by Wilcoxon signed-rank test.

and adhesion from the tissue reaction near the protruding mass, and interference with epiglottis movement [7].

Dysphagia with anterior cervical osteophytes can be managed conservatively or surgically. In previous studies, the first-line treatment for symptomatic patients was diet modification and postural changes during swallowing $[3,7,8]$. Surgical removal is reserved for patients with persistent symptoms, despite optimal medical management, and radiographic evidence suggesting functional swallowing impairment by the osteophytes $[3,7,8]$. Carlson et al. [1] reported that $9 / 9$ patients showed significant subjective swallowing improvement within three months after surgery, and Oppenlander et al. [9] reported that 9/9 patients experienced significant improvement of swallowing function in VFSS after osteophytectomies. Further, several case reports described improved swallowing after surgical removal [2].

Although the beneficial effect of surgical removal has been reported, surgical management for dysphagia is still controversial. First, surgery can aggravate dysphagia because laryngeal soft tissue edema and laryngeal nerve injury can occur during and after surgery [8]. Further, dysphagia cannot be resolved completely via the surgical approach in some cases with irreversible surrounding tissue changes due to longstanding progressive osteophytogenesis [3]. In addition, the indications for operative treatment have not been fully established.

This study describes the first kinematic approach to determine the effect of cervical anterior osteophyte surgical resection on swallowing function. One important limitation of prior studies is that quantifiable evidence is lacking. The present study demonstrated that surgical cervical anterior osteophyte resection could improve both swallowing function and the kinematic variables of laryngopharyngeal movement. In the follow-up VFSS at 8-12 weeks after surgery, the recommended diet and functional indicators of dysphagia (VDS) improved in 3 of the 5 cases and in 3 of the 4 cases who had required a modified diet before surgery. In case 4 , the VDS score was increased due to pharyngeal wall coating and delayed pharyngeal transit time after surgery. However, the pyriform sinus residue decreased and neither penetration nor aspiration were found. Aggravation in the pharyngeal constrictor function and pharyngeal trigger, however, requires special attention, because these can result as surgical complications affecting the pharyngeal nerve plexus. Previous studies reported similar functional improvement after surgical treatment. Carlson et al. [1] reported instant swallowing improvement with the chin-tuck posture after osteophytectomy in two patients and a significant improvement in dysphagia within three months following surgery in all of 9 patients. 
In our kinematic approach, significant increases in the maximal hyoid velocity, and upper esophageal sphincter opening width were observed after surgery. The maximal hyoid vertical movement also showed an increase with marginal significance. Further, fluid flow velocity improved in three cases. The upper esophageal sphincter opening and trans-sphincteric fluid flow are the essential parts of the normal pharyngeal phase of swallowing [10]. The upper esophageal sphincter is opened initially by hyoid traction via contraction of the suprahyoid muscles [10]. The elevation contributes to airway entrance closure, and the forward movement contributes to esophageal sphincter opening [10]. A more natural placement of the resting hyoid and decreased tension of the soft tissue surrounding the hyoid bone following surgery could explain the improvement in hyoid movement. This suggests that improved hyoid bone movement and enhanced bolus flow to open the upper esophageal sphincter might be the main positive effects of surgical resection. According to current results, laryngeal elevation exercises, and Shaker's exercises to enhance hyoid bone movement and upper esophageal sphincter opening would be effective in improving the swallowing abilities in these patients.

The current study has several limitations. First of all, the study size was too small to reach statistical significance. That is because it is clinically rare to surgically resect the osteophyte to solve dysphagia. Secondly, the effects of swallowing therapy could not be controlled because the cases were reviewed retrospectively. Thirdly, the followup period was only two months. Further prospective studies are necessary to clarify the kinematic variables with statically borderline significance and to define the long-term effects of surgical management for cervical anterior osteophytes.

In conclusion, improved upper esophageal sphincter opening via the enhancement of hyoid movement might be the kinematic mechanism of improved swallowing function after cervical anterior osteophyte resection. Therefore, evaluating whether delayed fluid flow or limited opening of the upper esophageal sphincter is the main element of dysphagia with anterior cervical osteophytes might be important in the consideration of surgical removal.

\section{CONFLICT OF INTEREST}

No potential conflict of interest relevant to this article was reported.

\section{REFERENCES}

1. Carlson ML, Archibald DJ, Graner DE, Kasperbauer JL. Surgical management of dysphagia and airway obstruction in patients with prominent ventral cervical osteophytes. Dysphagia 2011;26:34-40.

2. Lecerf $\mathrm{P}$, Malard O. How to diagnose and treat symptomatic anterior cervical osteophytes? Eur Ann Otorhinolaryngol Head Neck Dis 2010;127:111-6.

3. Miyamoto K, Sugiyama S, Hosoe H, Iinuma N, Suzuki Y, Shimizu K. Postsurgical recurrence of osteophytes causing dysphagia in patients with diffuse idiopathic skeletal hyperostosis. Eur Spine J 2009;18:1652-8.

4. Song J, Mizuno J, Nakagawa H. Clinical and radiological analysis of ossification of the anterior longitudinal ligament causing dysphagia and hoarseness. Neurosurgery 2006;58:913-9.

5. Kim DH, Choi KH, Kim HM, Koo JH, Kim BR, Kim TW, et al. Inter-rater reliability of videofluoroscopic dysphagia scale. Ann Rehabil Med 2012;36:791-6.

6. Paik NJ, Kim SJ, Lee HJ, Jeon JY, Lim JY, Han TR. Movement of the hyoid bone and the epiglottis during swallowing in patients with dysphagia from different etiologies. J Electromyogr Kinesiol 2008;18:329-35.

7. Angelos C, Dimitra A. Dysphagia due to anterior cervical osteophytes complicated with hypopharynx abscess. BMJ Case Rep 2011 Feb 23 [Epub]. http://dx. doi.org/10.1136/bcr.11.2010.3551.

8. Bilbao G, Duart M, Aurrecoechea JJ, Pomposo I, Igartua A, Catalan G, et al. Surgical results and complications in a series of 71 consecutive cervical spondylotic corpectomies. Acta Neurochir (Wien) 2010;152:1155-63.

9. Oppenlander ME, Orringer DA, La Marca F, McGillicuddy JE, Sullivan SE, Chandler WF, et al. Dysphagia due to anterior cervical hyperosteophytosis. Surg Neurol 2009;72:266-71.

10. Dodds WJ, Stewart ET, Logemann JA. Physiology and radiology of the normal oral and pharyngeal phases of swallowing. AJR Am J Roentgenol 1990;154:953-63. 